\title{
Discipline in Schools: Assessing the Positive Alternative Invitational Discipline Approach
}

\author{
Seakge Harry Rampa ${ }^{1, *}$ \\ ${ }^{1}$ Department of Educational Studies, Faculty of Humanities, Tshwane University of Technology, Private Bag X680, \\ Pretoria, South African \\ *Correspondence: Department of Educational Studies, Faculty of Humanities, Tshwane University of Technology, \\ Private Bag X680, Pretoria, South African. E-mail: rampash@tut.ac.za
}

Received: September 2, 2013

Accepted: June 11, $2014 \quad$ Online Published: June 25, 2014

doi:10.5430/wje.v4n4p20

URL: http://dx.doi.org/10.5430/wje.v4n4p20

\begin{abstract}
The study investigated whether positive alternative discipline approaches have improved the culture of teaching and learning in South Africa. The implementation of positive alternative discipline approaches encountered difficulties and challenges that plunged schools into crisis. The culture of teaching and learning subsequently deteriorated over the past years, notwithstanding various disciplinary interventions. Three hundred and thirty-three teachers of schools in the Mpumalanga province of South Africa participated in this quantitative survey. The questionnaires provided valid responses and an official statistician analysed and tested them using the Cronbach alpha coefficient to establish acceptable reliability. Findings reported the teachers' unwilling to implement alternative disciplinary approaches imposed upon them. Therefore, the study recommended the creation of a positive invitational framework flexible enough to accommodate differences among schools to improve the culture of teaching and learning. This recommended framework, customised based on the lived experiences of teachers, must become a mandatory component of a continuous review process for disciplinary improvement to occur.
\end{abstract}

Keywords: continuous improvement; culture of teaching and learning; customised framework; positive alternative discipline; positive invitational discipline; self-discipline

\section{Introduction}

Positive invitational discipline exists when learners at schools feel comfortable, wanted, valued, accepted, and safe and secure in an environment where they interact with caring teachers they trust (Dlamini, 2011). Continuous and effective implementation of this regime typically fosters self-disciplined learners accountable with dignity for their own learning. Achieving the desired outcomes requires a partnership with teachers who use the pedagogy of duty to care (Purkey \& Straham, 2005). Non-punitive, positive discipline necessarily involves the implementation of the self-concept theory underpins it. According to Purkey and Straham (2005), positive invitational discipline results when learners and role players in a school intentionally create environments and a climate that encourage people to think critically but favourably of themselves and how they think, behave, and act in various life roles, thus continuously improving the culture of teaching and learning (COLT). Naong (2007) argues that most teachers, not born with self-concept, but must continuously interact collegially with other role players to set norms and standards, resulting from teamwork, in collective and individual efforts, to demonstrate efficacy in teaching and learning. Adler and Dreikurs (2011) indicate that positive discipline focuses on supportive behaviours such as mutual respect, effective communication, collegial planning, setting standards, addressing the causes of misbehaviour, and constantly assessing the implementation of discipline.

In South Africa, a great deal of literature exists about school discipline, but few locally based research projects have sought to identify and evaluate the positive invitational disciplinary methodologies introduced by the Department of Education for schools after the prohibition of corporal punishment. An internet search revealed some global research in this field, but very little done in South Africa. To bridge this gap in the literature, necessitated a survey on positive invitational disciplinary practices in classroom management and school-wide positive behavioural support for South African schools. Although conducted in a South African context, the study results have global relevance. The study 
assessed the development and implementation of the recommended approaches by teachers to establish a positive COLT in schools.

After 1994, the national Department of Education introduced a non-punitive, positive and constructive approach to the maintenance of discipline in the schools (Naidoo, 2004), which implicitly or explicitly banned corporal punishment as a form of discipline. However, the implementation of alternative disciplinary approaches met with difficulties and challenges as learners reject any kind of authority; with the result that the phenomenon of 'pupil power,' as a form of entitlement, led to intimidation and violence. The question then arose: Do South African teachers have the knowledge, skills and competence to implement alternative disciplinary approaches? The new regime premised that teachers need to create pedagogy of care, not as educational philanthropy, but as the obligatory duty of effective teacher to care. For this purpose, prevention strategies to achieve learner outcomes and school-wide disciplinary plans for teachers provide the glue to unify expectations and consequences for acceptable behaviour fostering learner success.

South African learners' misbehaviour and teachers' uncertainty about how intentionally to develop and implement alternative disciplinary approaches have resulted in vandalism, violence, social aggression, revenge, retaliation against school authority, open disrespect, and disobedience of school rules (Naidoo, 2004). As a result, a number of schools, torn by crisis, have experienced the deterioration or collapse of their culture of learning over the past few years. The results of the survey revealed clearly that the participants did not know how to identify and implement strategies to reverse the decline and respond to the challenge. This descent into near chaos negatively affected the entire educational environment and nullified the fulfilment of the schools' mission.

Teachers from three regions of Mpumalanga, selected through cluster sampling, agreed to share the insights about an integrated positive invitational framework, one accommodating of differences in and among schools and adaptable to South Africa's conditions. The questions guiding the research firstly inquired whether a culture of teaching and learning existed at the school; and, secondly, whether the school had implemented positive alternative disciplinary (PAD) approaches. The responses to these questions informed the preparation of the conceptual framework on positive invitational discipline.

\section{Theoretical Framework}

To ascertain whether the adoption and implementation of a positive invitational discipline (PID) framework could rectify the problematic school discipline at schools, the research strategy included an imperative to focus on theories that explain the discipline itself. The first group explained positive alternative disciplinary changes, such as theories regarding self-concept which support new approaches to discipline. The second included the quantitative theories on the post-positivist worldview (Naong, 2007; Purkey \& Straham, 2005). These theories operationalise the assumptions of post-positivism knowledge about disciplinary intervention positing that teachers must understand the nature of their role as well as relevant change theories to describe and determine the frameworks for effective teaching and learning. According to the relevant research (Purkey \& Straham, 2005), the processes and outcomes of making claims, refining or abandoning some forms of discipline, and explaining the rationale for accepting considerations for inclusion enable the implementing teachers and supervisors to shape knowledge and seek relevant and valid theory statements that explain undergird the newly adopted disciplinary processes. As a result, these collaborative activities, all participants have a common understanding of the theories thus facilitating continuous improvement of the quality of teaching and learning.

For historical background, the study drew upon the experience of Christian National Education (CNE), with the shared purpose of maintaining control to protect and preserve the culture of teaching and learning with order. Learners suffered consequences for wrong-doing; often involving punitive discipline, frequently of a physical nature. The CNE rationale premised altered and acceptable behaviour of learners who incurred the penalties for disobeying school rules. Instead, however, the CNE approach to discipline led to feelings of revenge, anti-social aggressiveness, and even acts of violence amongst learners (Naidoo, 2004). Overall, school discipline virtually failed to preserve order and protect the culture of teaching and learning.

After 1994, the Department of Education abolished corporal punishment in schools. Section 12 of the South African Constitution states that everyone has the right to treatment with dignity and respect. The Department encouraged teachers to adopt and apply non-violent, constructive, and positive disciplinary approaches, such as withdrawal of privileges, behavioural modification, time-out for misbehaving learners, and preventative, corrective, and supportive disciplinary methods (Department of Education, 2001; Squelch, 2000). 
The new regime mandates teachers to use discipline proactively in teaching learners to accept authority, adhere to school rules, exercise self-control, and respect others (Ngwenya, 2007). Charles (2012) indicates that the proactive disciplinary management approach has the potential to create order and ensure harmonious relations and activities for both teachers and learners. This change in approach to school discipline also has the potential to sustain a safe and secure environment in schools. The previous statement rests on the premise that learners, who grow up in such environments, on an average do well academically, behave courteously, exhibit kindness to others and thrive as a result. School discipline has the primary aim all role players to participate collegially in developing self-discipline and creating environments for innovative learning, not simply for compliance itself. Quite clearly, learners and role players at schools collectively need to reach a point where they can look beyond 'what is' and become innovative to create a total teaching environment. Teachers must model and communicate caring for duty to care as well to nurture the learner potential for responsible citizenship.

Although the Department of Education mentions some PAD approaches available for use by teachers, such as preventative, supportive, and corrective reinforcements and progressive discipline character development (Department of Education, 2001), schools nonetheless must develop their own innovative disciplinary codes of conduct to satisfy their specific needs. Learners must participate in an interactive process to develop their character strengths and virtues with self-discipline. Figure 1 illustrates the PAD approaches as a basis for the theoretical framework employed in this study.

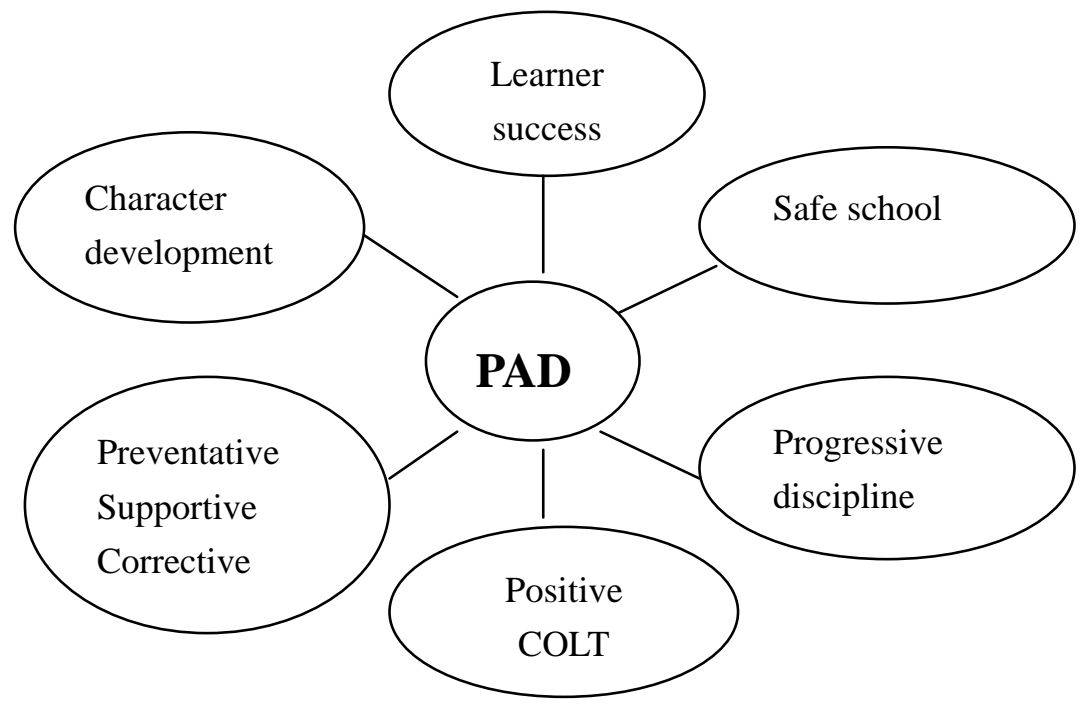

Figure 1. Basis for Theoretical Framework: Positive Alternative Discipline

Teachers have the responsibility to identify, implement and support creative and positive disciplinary practices reflective of their school's unique systems of belief and values. Unfortunately, teachers lack adequate knowledge of and skills in identifying and implementing PAD approaches, and failure to address that deficit surely exerts a negative effect on the school's disciplinary practices. Masango (2005) indicates that the lack of discipline in schools has essentially destroyed the socially interactive, interrelated, and integrated accountability that heretofore upheld a common code of appropriate behaviour. He argues further that schools' insufficiently developed learning environments and culture have contributed to the learners' present standards of behaviour and performance. Only the consistent application of school codes and an inability to apply and maintain PAD procedures offer the promising means to address to resultant challenge to effective teaching and learning.

Lubisi (2004) criticised the PAD forms of discipline imposed on teachers by the Department of Education because of their difficult and time-consuming implementation demands; schools lacked the time, expertise, and resources to implement them successfully. Zwane (2004) further faulted these alternative disciplinary approaches for their ineffectiveness in curbing learners' misbehaviour and ill-discipline, largely because they failed to empower teachers through continued professional development and training in disciplinary procedures. Teachers required to implement the new approaches constantly felt the pressure of the reforms but experienced a lack of support (Naong, 2007). It seems clear then that teachers lack the necessary capacity to manage and handle discipline in the schools. Steyn 
(2012) asked how to make schools intentionally inviting, and proposed professional development (empowerment) based on positive approaches. Based on the available research, it remains to be seen, it remains unclear whether teachers resist the implementation of the PAD approaches or simply lack the requisite skills and knowledge. To resolve that question, this study surveys teachers' perceptions of the introduction and implementation of the PAD approaches to restore discipline in South African schools. The study analysed the validity of the hypothesis that understanding of the inadequacy of the teachers' disciplinary knowledge, skills, and experiences explains their frustrations with the implementation of PAD procedures in the schools. Further, the researcher relied on the results of the study to construct an empirical design of a flexible PID framework that accommodates differences in and among schools.

\section{Empirical Design}

Survey questionnaires solicited relevant information about conditions in the schools, familiarity with PAD approaches, and individual perceptions about discipline from the teachers of the three regions of Mpumalanga, South Africa, namely Gert Sibande, Ehlanzeni, and Nkangala. Specifically, the survey questionnaire asked the teachers 1) about the attributes of the COLT in their schools; and 2) their perceptions of how and why PAD approaches will improve the COLT? The research strategy relied on cluster sampling (De Vos, 2002) to select schools. The selected contiguous circuits in the three regions have urban and rural schools in common and share the COLT characteristics found in other circuits, thus facilitating generalisation of the results. The De Vos (2002) guidelines also supported randomly selection of 32\% of the teachers in each region as representative participants. From the population of 1041 , deputy principals, heads of departments, and post level 1 teachers, the sample included a total of 333 teachers who received the questionnaires. The research procedures also included considerations of respondent autonomy, anonymity, and privacy to comply with research ethics. Respondents also received written confirmation of the right to withdraw from the research at any time without consequences.

The official statistician designed and assisted with the analysis of the information and data derived from the responses to the questionnaire. He used Cronbach's Alpha coefficient of reliability and factor analysis and derived a reliability coefficient value of .7, deemed acceptable. The statistical methodology employed a four-point Likert scale to categorise and rank the responses to each question; subsequently merging 'strongly agree' with 'agree' responses and 'strongly disagree' with 'disagree' responses into two polar opposing types of responses for analytical purposes. In addition, the tables below present the 'agree' response percent (\%) ranked in descending order to identify the areas needing immediate improvement. The positive statements in tables 1-4 identify the conditions desired in the schools, according to the PAD, and the negative responses (agree \% less than 60) identify the conditions not yet sufficiently established. Quantitative data, computed into frequencies, facilitated the analysis and interpretation in accordance with the research focus. The questions that guided the study asked 1) whether COLT exists in the schools; and 2) whether the Mpumalanga schools had implemented PAD approaches. The researcher expected the teachers' responses to reveal whether teachers used PAD approaches effectively in developing an environment conducive to COLT. It seemed important as well to determine whether teachers had prior knowledge of these approaches and the skills required for their implementation.

\section{Results}

The methodology involved organising the findings under the following rubrics: biographical aspects, teachers' experiences with positive COLT, teachers' opinions regarding their school's code of conduct, teachers' own personal experiences with PAD approaches, and teachers' roles in school disciplinary problems.

\subsection{Biographical Data}

The profile respondents, $37 \%$ of the total number of teachers in the selected circuits, had occupied their current posts for 5-10 years. As either highly or fairly experienced teachers, as a group they had undergone and survived the struggle for democratic education in schools and as a result brought direct personal knowledge about the historical development of, and reasons for the lack of, school discipline. Sixty-five per cent of the respondents indicated that they had received training in PAD measures; 54 \% through workshops organised by the Department of Education, and $35 \%$ through continued professional development from various institutions of learning. Clearly, the majority of teachers have some prior knowledge about alternative disciplinary methods and some experience with its implementation in the classroom. This training and experience certainly influenced their perceptions of discipline in the schools. 


\subsection{Teachers' Opinions About a Positive Culture of Learning and Teaching In Schools}

The tables below indicate the 'agree' response ranked in descending order to identify immediate priorities disciplinary improvement.

Table 1. Teachers' Opinions of Whether the Characteristics of Positive Culture of Teaching and Learning Exist

\begin{tabular}{lccc}
\hline $\begin{array}{l}\text { Statements: Characteristics of positive culture of learning } \\
\text { and teaching }\end{array}$ & Agree \% & Priority \\
\hline $\begin{array}{l}\text { A safe school environment free of violence, ill-discipline, drug abuse, and } \\
\text { maintenance of orderly working environment }\end{array}$ & 34 & 1 \\
$\begin{array}{l}\text { A positive school climate of cooperation and participation between teachers, learners, } \\
\text { and parents }\end{array}$ & 42 & 2 \\
$\begin{array}{l}\text { A positive two-way communication channel that invites and motivates parents to } \\
\text { attend school disciplinary meetings }\end{array}$ & 44 & 3 \\
$\begin{array}{l}\text { High expectations for learners, such as regular attendance, punctuality, hard-working, } \\
\text { and accepting authority }\end{array}$ & 47 & 4 \\
\hline
\end{tabular}

The teachers' responses accorded highest priority for immediate attention to school safety and an orderly working environment. The responses also exhibited the teacher concern about the willingness of parents to become involved in and engaged with the schools, or to attend schools' disciplinary meetings and encourage learners' regular attendance and acceptance of school authority. Because they found themselves unable or unwilling to develop a positive, participatory school environment inviting both learners and parents to participate in school regulatory processes; teachers also found it impossible to ensure conditions for learner's development and the maintenance of an orderly working environment in the schools. The survey responses reveal a very clear and serious effect on the COLT in the schools, perhaps even subverting the COLT entirely. Purkey and Straham (2005) and Hollins (1996) assert that schools develop, implement, sustain a robust COLT by operationalising principles such as open communication, high expectations for learners, and invitational participation. Furthermore, Steyn (2012) strongly suggests the need for teacher professional development on innovative and interactive engagement of role players in order to establish acceptable discipline in intentionally inviting schools.

\subsection{Teacher' Opinions Regarding the Schools Code of Conduct}

Table 2. Teachers' Opinions of Whether the School Code of Conduct Exists

\begin{tabular}{lll}
\hline Statements: School code of conduct & Agree \% & Priority \\
\hline $\begin{array}{l}\text { Role players understand how to develop and implement the code of conduct } \\
\text { according to the SASA, Section } 20 \text { that requires cooperative participation and } \\
\text { discipline with respect for human dignity. }\end{array}$ & 13 \\
$\begin{array}{l}\text { The process of keeping and maintaining the code of conduct presents an enjoyable } \\
\text { responsibility in the school as all role players regard the code as their shared and core } \\
\text { values. }\end{array}$ & 30 & 2 \\
$\begin{array}{l}\text { Teachers effectively use the code of conduct in curbing learners' ill-discipline and } \\
\text { misbehaviour. }\end{array}$ & 36 & 3 \\
$\begin{array}{l}\text { Parental and professional support services such as police and social workers stand } \\
\text { always available to support the school code of conduct. }\end{array}$ & 37 \\
$\begin{array}{l}\text { Teachers have the knowledge and skills to implement the school code of conduct } \\
\text { democratic processes. }\end{array}$ & 39 & 5 \\
\hline
\end{tabular}

This section of the questionnaire received the largest number of negative responses. This outcome strongly suggests that the teachers do not yet understand that the implementation of the robust and effective school codes of conduct required by Section 20 of the South African Schools Act depends upon the active support of all role players, specifically including teachers. Because of the lack of teacher understanding and involvement, these schools have failed to develop and implement effective codes and use them to describe and secure support for appropriate 
behaviours. The responses indicated, too, that many of the teachers lacked the knowledge of and skills in implementing the basic democratic processes the school code of conduct requires, such as careful investigations, open hearings and the right of appeal. Therefore, the teachers have not used the codes effectively to curb learners' ill-discipline; and misbehaviour. This dysfunctionality undermined the codes and led to their inconsistent and desultory implementation. As one of its most critical functions, the code of conduct describes and sanctions appropriate learner behaviour in schools. Teachers must have preparatory training in appropriate training in appropriate discipline approaches and continuous professional development to remain aware of the dynamic and changing roles they have to play in the development, implementation, and maintenance of the codes of conduct in schools.

\subsection{Teachers' Opinions Regarding Positive Alternative Disciplinary Approaches}

Table 3. Teachers' Opinions of Whether Positive Alternative Disciplinary Approaches Exist

\begin{tabular}{lll}
\hline Statements: Positive alternative disciplinary approaches & Agree \% & Priority \\
\hline $\begin{array}{l}\text { Teachers assume leadership roles in correcting learners' behaviour and handling } \\
\text { disciplinary problems. }\end{array}$ & 20 & 1 \\
$\begin{array}{l}\text { Teachers use disciplinary records for misbehaving learners and explain the rules and } \\
\text { consequences of breaking them. }\end{array}$ & 26 & 2 \\
$\begin{array}{l}\text { Teachers use corrective discipline for learners who transgress the school rules. } \\
\text { Teachers use the code of conduct as the internal rule of law within the school. }\end{array}$ & 28 & 30 \\
$\begin{array}{l}\text { Teachers have skills and knowledge in implementing alternative positive disciplinary } \\
\text { methods. }\end{array}$ & 31 & 4 \\
$\begin{array}{l}\text { The school cooperates effectively with professional support services in implementing } \\
\text { these approaches. }\end{array}$ & 35 & 6 \\
\hline
\end{tabular}

Table 3 shows that the surveyed schools have not yet enabled and empowered the teachers to implement the PID approaches efficiently and effectively, thereby failing to fulfil the mandate of the Department of Education. The efforts made by the teachers towards the implementation of PID approaches in schools ranged from 20 to 35\%; indicating that the teachers found it difficult to understand and effectively implement these approaches. Charles (2005) states that teachers, as decisive and powerful human resources in schools, must take ownership and help to create and maintain a supportive school environment. From that perspective, it seems reasonable to infer that the Department of Education's vision of developing a safe and disciplined school environment conducive to teaching and learning remains the challenge for the schools and the teachers. Although most teachers (65\%) received at least some training in alternative disciplinary approaches, the teachers found that the training did not enable them to understand and effectively implement the approaches. The Department of Education and the schools, especially the principals, must find ways to address the teachers' knowledge and skills deficits, concerns, and frustrations through professional development in order to gain the teachers' commitment and dedication.

\subsection{Teachers' Opinions Regarding Teachers' Role In School Disciplinary Problems}

Table 4. Teachers' Opinions Regarding Teachers’ Role in School Disciplinary Problems

\begin{tabular}{lll}
\hline Statement: Teachers' role in school disciplinary problems & Agree \% & Priority \\
\hline $\begin{array}{l}\text { Teachers lack adequate skills and knowledge for the new disciplinary regime } \\
\begin{array}{l}\text { Teachers do not understand disciplinary procedures that do not rely on corporal } \\
\text { punishment }\end{array}\end{array}$ & 45 & 3 \\
$\begin{array}{l}\text { Teachers lack interest and commitment in learning new procedures and trends } \\
\text { regarding discipline at schools. }\end{array}$ & 52 & 2 \\
$\begin{array}{l}\text { The school disciplinary problems demoralised teachers and caused them to use } \\
\text { corporal punishment. }\end{array}$ & 57 & 1
\end{tabular}

Seeman (2008) argues that inappropriate teacher personalities, disciplinary approaches, and teaching styles, and interactions with learners contribute to learner disciplinary problems. The predominantly negative comments in Table 4 suggest as well that that the teachers who participated in the survey have no interest in learning new and 
innovative methods to manage their classes. The teachers' responses also manifested a serious lack of interest in and passion for teaching, thereby contributing to the deterioration of discipline in the schools. Teachers agreed that the proliferation of the acts of learner violence, threats, and retaliation caused them to lose interest in teaching. They indicated further that, as a direct result, they ignored their responsibility for discipline and simply left that difficult and challenging task to parents or administrators. The refusal to accept accountability for discipline undoubtedly created the authority vacuum that allowed shocking incidents of learner misbehaviour, such as drinking alcohol, vandalism, and carrying and using dangerous weapons in the schools. Thus schools inevitably became unsafe for all role players.

The lack of teacher empowerment in the professional role of maintaining order in schools becomes clear from a review of the information that the teachers provided in their responses to the survey questionnaire. In that regard, Van der Horst and Mc Donald (2007) stated that, in the absence of established authority within the classroom and the school, learners take control and determine when and how teaching and learning occur. Similarly, when teachers decide the rules without consulting learners, learners tend to ignore or circumvent rules in which they have no ownership. If pertinent and valid, as they seem, these assumptions and observations pinpoint teacher empowerment as the quintessential feature of the working relationships between teachers and learners. To succeed in their assigned mission, therefore, schools must accept and successful accomplish the task of developing and empowering teachers to fulfil their professional roles concerning discipline in the school and the classroom.

\section{Discussion}

The findings in this study show that, for a variety of reasons, the implementation of PAD programmes does not meet the expectations of role players in schools. Moreover, the survey results suggest as well that the failure to establish effective disciplinary programmes flowed directly from the lack of collegiality and synergy among the critical role players. Further, the findings reveal that a programme that work in one particular setting may not work in another. Based on these findings, it seems clear that an effective and responsive disciplinary framework must have the flexibility to maximise the learning potential within the participatory practices of teachers by recognising that different teachers frequently respond differently to the same circumstances.

Fulfilling the purposes of the study required the identification of the major trends that have prevented the establishment of PAD and PID programmes in the schools surveyed, and to highlight priorities for attention and action. In addition, the researcher subsequently used the study results to recommend a framework for implementing PAD and PID approaches to school approaches to school discipline of resisting solidly on assuring that the critical role players 1) understand the underlying theories of collaborative interaction, and 2) of respect meaningful self-discipline, both essential to the implementation of PAD and PID approaches.

COLT: The data analysed revealed clearly that the schools in the survey lacked safety and security and a harmonious working environment; just as Herzberg's two factor theory predicts (Van Deventer \& Kruger, 2004). Moreover, Hertzberg's theory holds as well that the contributing hygiene factors such as salary, supervision and environment, seriously compromise the quality of life and job satisfaction of teachers (Mafora \& Schulze, 2012). As a result, because teachers cannot develop and function in a participatory environment, they turn inwards and work in silos. This evasive response undermined their authority and left them despondent and apathetic. The atrophied Colt lacked the power to support effective teaching and learning.

Efficacy: Equally clear, the resulting conditions prevented the development of the teacher-learner relationships demanded by PAD and PID approaches. Mokhele (2011) attributed poor teacher-learner relationships to 1) teachers' inadequate knowledge about the effective use of PAD approaches; and 2) an exclusive reliance on power to establish authority. The knowledge inadequacy manifest itself in the inattention to the instructional duty for nourishing care in the teaching instructional processes specifically to help learners accept responsibility for their own learning. This pedagogical or instructional deficiency stimulates learner dependency rather than self-reliance because of the lack of appropriate socio-psychological development (Schoeman \& Mabunda, 2012); and for teachers, thwarts cooperation and synergy between the schools, and the home and the communities. These negative outcomes ensue directly from the teachers' inability to understand and collegially to implement PAD and PID approaches.

The codes: It follows that the teachers who participated in the study did not understand PAD approaches and failed to implement them because they lacked the requisite knowledge, skills and abilities. In addition, there were as a consequence, no new codes of conduct existed to inspire innovative learners, and teachers experienced a deterioration of commitment and collegiality. 
Problem: Based on the above, the researcher recommends the development and application of a PID framework for use in the creation of a new PAD approach to resurrect and enhance the COLT. The framework is based on and draws on the relevant literature and the empirical findings of this study for use as a guide a guide to design, set standards for, implement, and evaluate a plan involving delegation, open communication, and a cooperative decision-making process. This framework accommodates differentiation, has the flexibility accommodate differences as well as common features based on local conditions, and precludes a one-size-fits-all model.

In specific, the recommendation proposes to take account of how teachers view and experience the development and implementation of the PAD approaches. The first step requires remediation of the serious knowledge and skill deficiency of the teachers by providing targeted professional development. The PAD proposed by the Department of Education for implementation in all schools sought similar results, but the results of this study demonstrates the need for proper preparation prior to implementation. While some schools' improved the COLT, in others the COLT deteriorated. Most importantly, the recommendation proposes a framework focused sharply on the teachers. As mentioned, its flexibility accommodates differences among schools and it builds upon the premise that a classroom, as the critical teacher-learner interactive space in the schools, and provides the environment, the implementation and maintenance of discipline to encourage, support, instruct, and model appropriate school behaviour and citizenship. The appropriate maintenance of discipline inside the classroom extends an expectation and a positive invitation with powerful potential effect outside the classroom, thus contributing to an effective COLT.

The proposed framework involves three major interlinked and interrelated principles: classroom discipline planning, discipline standard setting, and the implementation and evaluation of school discipline. This framework rests solidly on the lived experiences of participants in this study.

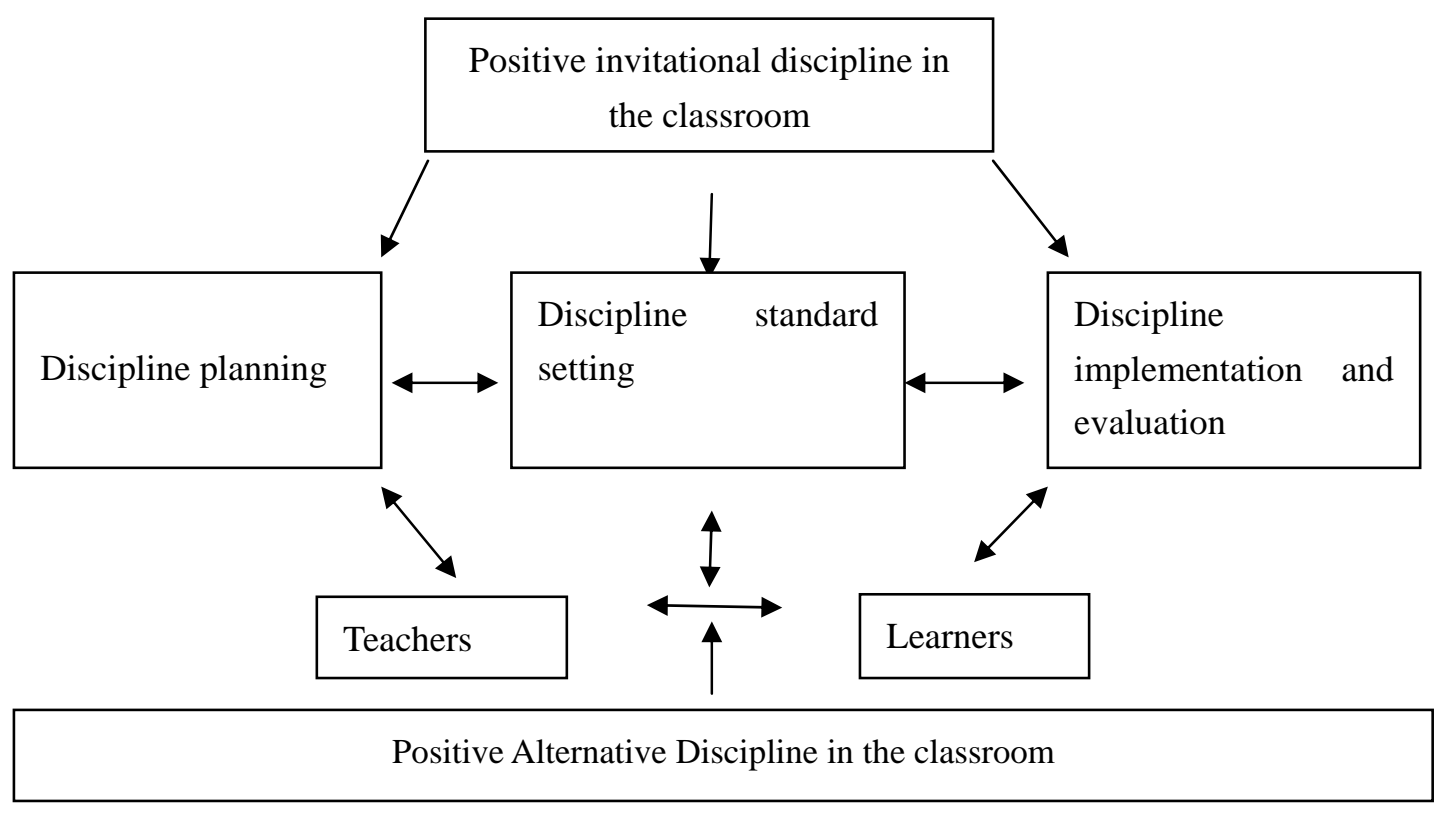

Figure 2. A Customised Positive Invitational Discipline Framework

On the basis of the findings from literature and empirical survey, a need arose based on the major trends that prevented the establishment of PAD approaches and PID programmes in the schools surveyed to customise PID framework. The PID framework promotes the development of the teacher-learner relationships, cooperation and synergy between schools, the home and the communities thereby positing that in discipline planning, teachers plan, study, and act on the plans to know and understand their PAD approaches. Knowing the PAD approaches, helps the teachers in planning, developing the expected PID programmes for the purposes of classroom life vision and establishing classroom norms and values that guide the design of the set PAD standards. The teacher plans and organises the PID programmes according to learners' needs and organises the classroom settings in a way that allows for cooperative learning and placing a misbehaving learner in a position where the teacher will always have contact with the learner for quick guidance and warnings. During discipline planning, teachers need to involve learners through classroom discussion and dialogue and to regard them as partners in the formulation processes. As mentioned earlier, its flexibility to accommodate differences, it builds upon the premise, critical-learner interactive 
space as well as providing the environment and maintenance of discipline and model appropriate school behaviour.

It follows then that in the disciplinary standard setting, the teachers understand collaborative interactions that guide, openly engage and teach learners the agreed-upon class codes, values and norms and set behavioural standards. The teacher teaches learners that their behaviour has consequences and that they respect meaningful self-discipline responsible and accountable for the outcomes of their chosen behaviour, both essential to the implementation of PAD and PID approaches. During this phase learners are given responsibilities in the form of delegated classroom activities to the instructional duty for nourishing care to help learners accept personal responsibility, accountability, mutual trust and respect. Although teachers are central figures in PAD and PID programmes in standard setting, learners are involved through classroom interactive space and the delegation of class authority and activities in developing a disciplined classroom community.

In the implementation and evaluation of PID programmes, the teachers' role shifts towards making sure and keeping learners actively engaged in class activities in order to minimise learners' misbehaviour and disturbance caused by them. This is done through the installation of appropriate PAD approaches and procedures such as the delegation of tasks and duty to care inside the classroom and extends an expectation of a PID programme. During this phase, the teachers monitor whether or not learners observe PAD standards, class norms and re-direct learners' unacceptable behaviour leading to the PID programmes. Behavioural PAD approaches such as reinforcement, remedial consequences and teacher-learner dialogue are used by the teacher if the teacher observes that learners do not keep to the agreed-upon codes of behavioural standards. In this phase teachers are actively involved through keeping PAD approaches and assisting learners through PID programmes preventing them from misbehaving.

The study recommends that the PID framework should be part of a continuous review process for it to be a useful tool for PID improvements of COLT. This is because how learners behave, observe class codes and engage in class activities influence the teachers' PAD re-planning and the establishment of new class codes, values, norms and disciplinary standards. If learners continue to misbehave, do not observe school codes and do not actively engage in school activities, the teacher needs to start again and progress from disciplinary planning to standard setting. An end, then becomes a new beginning through engagement and total involvement of the learners and the school community. Learners' positive behaviour would then mean that the teacher's PAD planning, setting of disciplinary standards, the teaching of values and norms, class codes and delegation processes are successful. Teachers can therefore continue with their roles of monitoring classroom codes and re-directing learners' unacceptable behaviour through the use of PID approaches, requisite for knowledge, skills and abilities for self-discipline

PAD strategies should be reviewed and new ones be adopted if the PID does not develop as expected. This is part of an evaluation process that needs to be carried out regularly and whereby success is acknowledged and corrective measures are taken immediately. The continuous review process of the framework and the participation and involvement of learners and parents may improve the PAD knowledge of the school community leading to positive COLT. Thus collegial teamwork, cooperation and synergy necessary to find effective PID programmes are established. This makes the proposed framework different from PAD approaches as it is classroom based, interactive and useful in schools.

It follows that supporting and developing teachers in the implementation of the PID framework might ensure that they are given effective PAD principles to inculcate in learners' self-discipline, responsibility and accountability for the outcomes of their chosen behaviour. The theory of self-concept underpins those principles and teachers therefore scaffold the task of setting the PAD space.

\section{Conclusion}

The adoption of the positive invitational discipline (PID) framework and teachers' duty to care may lead to learners who are self-disciplined and accountable for their learning and have dignity. This is because the teachers' intentionally and collegially create an environment for self-efficacy that promotes and nurtures the dynamic culture of teaching and learning (COLT). A suitable invitational framework for different contexts of schools provides a more expansive learning environment in diverse and wide-ranging learning opportunities that support and value learning. The results of the research have thus revealed that each school needs to understand the COLT and the implications of the positive alternative disciplinary (PAD) approaches to learning and thus engage collegially to ensure the support and expectations of suitable and appropriate behaviours. To this end, the setting of standards, the total school environment and the creation of a PID programmes promote self-discipline and the continuous review based on the emerging and current trends, thus showing how dynamic the suggested PID framework is when supported by a nurturing school culture and the successes of self-discipline. It is suggested that further research be conducted on the 
implementation of the PID proposed framework for schools.

\section{References}

Adler A., \& Dreikurs R. (2012). Positive discipline: A non punitive discipline system. RMLE Online, 35, 1-14.

Charles CM. (2005). Building classroom discipline. New York: Longman.

Charles CM. (2012). Building classroom discipline $\left(2^{\text {nd }}\right.$ Ed.). New York: Longman

Department of Education. (2001). Alternatives to corporal punishment: The learning experience. Pretoria: Government Printers.

De Vos AS. (2002). Research at grass roots. A primer for the caring professions. Pretoria: Van Schaik.

Dlamini JD. (2011). Discipline in Education: Assessing the Positive Discipline Approach in Selected schools in Mpumalanga Province. Unpublished D. Ed Thesis. Pretoria. Tshwane University of Technology

Hollins ER. (1996). Culture in school learning: Revealing the deep meaning. New Jersey: Lawrence Erlbaum Associates, In Keat A. 2002. The Teacher, 7, 7-16.

Lubisi C. (2004). Alternative to corporal punishment. The Star, 20, 22.

Masango S. (2005). Representative learners’ council indaba. Mpumalanga Newsletter, 2, 16-17.

Mafora TP., \& Schulze S. (2012). The job satisfaction of principals of previously disadvantage Schools: New light on an older issue. South African Journal of Education, 32, 227-239.

Mokhele PR. (2011). The teacher-learner relationship in the management of discipline in Schools. Africa Education Review, 3, 148-159. http://dx.doi.org/10.1080/18146620608540448

Naidoo T. (2004). Alternatives to corporal punishment. Mpumalanga Province: Nelspruit.

Naong M. (2007). The impact of the abolition of corporal punishment on teacher morale 1994-2004. South African Journal of Education, 27(2), 283-300.

Ngwenya N. (2007). Pupil who shot cop expelled. City Press, October 14:7.

Purkey WW., \& Straham DB. (2005). Inviting Positive Discipline. Columbus, OH: NMSH.

Schoeman S., \& Mabunda PL. (2012). Teaching practice and the personal and socio-professional development of prospective teachers. South African Journal of Education, 32, 240-254.

Seeman G. (2008). Positive attitudes at work. Creating a healthy organization. Blackwell Business.

Squelch J M. (2000). Discipline. Department of Education Management. University of Pretoria: L.M. Printers.

Steyn GM. (2012). Creating intentionally inviting schools through professional development: An appreciative inquiry. Koers, 75, 873-897.

Van der Horst H., \& McDonald R. (1997). Outcomes-based education: A teachers' manual. Pretoria: Kagiso Publishers.

Van Deventer I., \& Kruger AG. (2004). An educator's guide to school management skills. Pretoria: Van Schaik.

Zwane P. (2004). Alternative to corporal punishment. The Star, 20, 22. 